\title{
Internal Loop Recording of Prolonged (39 Second) Sinus Pause Causing Syncope
}

\author{
G. Pate* \\ Department of Cardiology, The Galway Clinic, Galway, Ireland
}

${ }^{*}$ Corresponding Author: G. Pate, Department of Cardiology, Suite 28, The Galway Clinic, Doughiska, County Galway, Ireland; Tel- 087 630 8888; E-mail: gordon.pate@ galwayclinic.com

Received: February 11, 2020; Accepted: February 20, 2020; Published: February 28, 2020

\begin{abstract}
Presentation: A 53 year old woman presented with a syncopal episode which occurred whilst sitting in bed reading, witnessed by her husband. She was unrousable for maybe half a minute. She had no other medical history, clinical examination was unremarkable, as were multiple investigations.
\end{abstract}

Diagnosis: A loop recorder was inserted without difficulty. A few weeks later she again blacked out. Her loop recorder showed asystole for 39 seconds, followed by a return to sinus bradycardia and then sinus rhythm, accompanied by recovery of consciousness.

Treatment: She went on to have a dual chamber pacemaker inserted. At review after six weeks, six months and one year she had had no further syncopal episodes.

Conclusion: This case reports one of the longest documented episodes of asystole with spontaneous recovery and serves as a reminder of the utility of internal loop recorders in the investigation of syncope.

\section{Introduction}

This case reports a patient with syncope in whom an internal loop recorder revealed one of the longest documented episodes of asystole with spontaneous recovery.

\section{Case Report}

A 53 year old woman presented with a syncopal episode which occurred whilst sitting in bed reading, witnessed by her husband. She was unrousable for maybe half a minute. She was a non-smoker, on no medications. Her father had a pacemaker inserted in his 70s, for slow atrial fibrillation; there was no family history of sudden adult death. She had no other clinical history; specifically, nothing to suggest sarcoidosis, haemochromatosis or other deposition disorders. Clinical examination was unremarkable. Multiple investigations, including echocardiography, electroencephalography and Holter monitoring, were essentially normal, as was brain magnetic resonance imaging. A Medtronic Reveal LINQ $^{\mathrm{nx}}$ loop recorder was inserted without difficulty. A few weeks later she awoke as usual, went to the toilet, micturated and returned to bed feeling fine. Whilst lying in bed, she again blacked out. She recovered consciousness a while later, and felt nauseated with a slight headache. That morning she was contacted by the hospital and advised to come in directly. Her loop recorder showed prolonged asystole! Figure 1 . She had gradually developed sinus bradycardia and then sinus arrest. After 39.4 seconds she returned to sinus bradycardia and then sinus rhythm without any compensatory tachycardia. There was no ventricular escape rhythm, simply a sinus pause with no rescue. The next day she was brought to the operating room for pacemaker insertion under local anaesthetic. Just after left subclavian vein cannulation, she had another 20 second pause, though she recovered before external pacing could be initiated. She regained consciousness and went on to have a dual chamber pacemaker inserted, with good thresholds in the right ventricular apex and right atrial appendage. At review after six weeks, six months and one year she had had no further syncopal episodes.

\section{Discussion}

Loop recorders have proved very useful in documenting previously unrecognized arrhythmias, particularly intermittent pauses [1]. Current guidelines recommend loop recorder insertion for any unexplained syncope [2]. In the event of documentation of any symptomatic pauses greater than 3 seconds, or nocturnal pauses greater than 6 seconds, pacemaker insertion is recommended [3]. Anything more than 10 seconds is described as a very long pause. Multiple papers have documented pauses of 10 seconds or more [47], including one of 44 seconds [8]. During a tilt table test one paper described asystole for 72 seconds [9], but this was a provoked pause and cardiopulmonary resuscitation was commenced so this cannot truly be described as spontaneous recovery of rhythm. Another consideration here was of artefact, a recognized issue with loop recorders [10]. However, the patient's clinical picture was consistent with the observed pause, she had not been undertaking any activity that might have produced an artefactual pause, and the fact she had another witnessed pause of 20 seconds in the hospital confirm that the observed pause was real. 

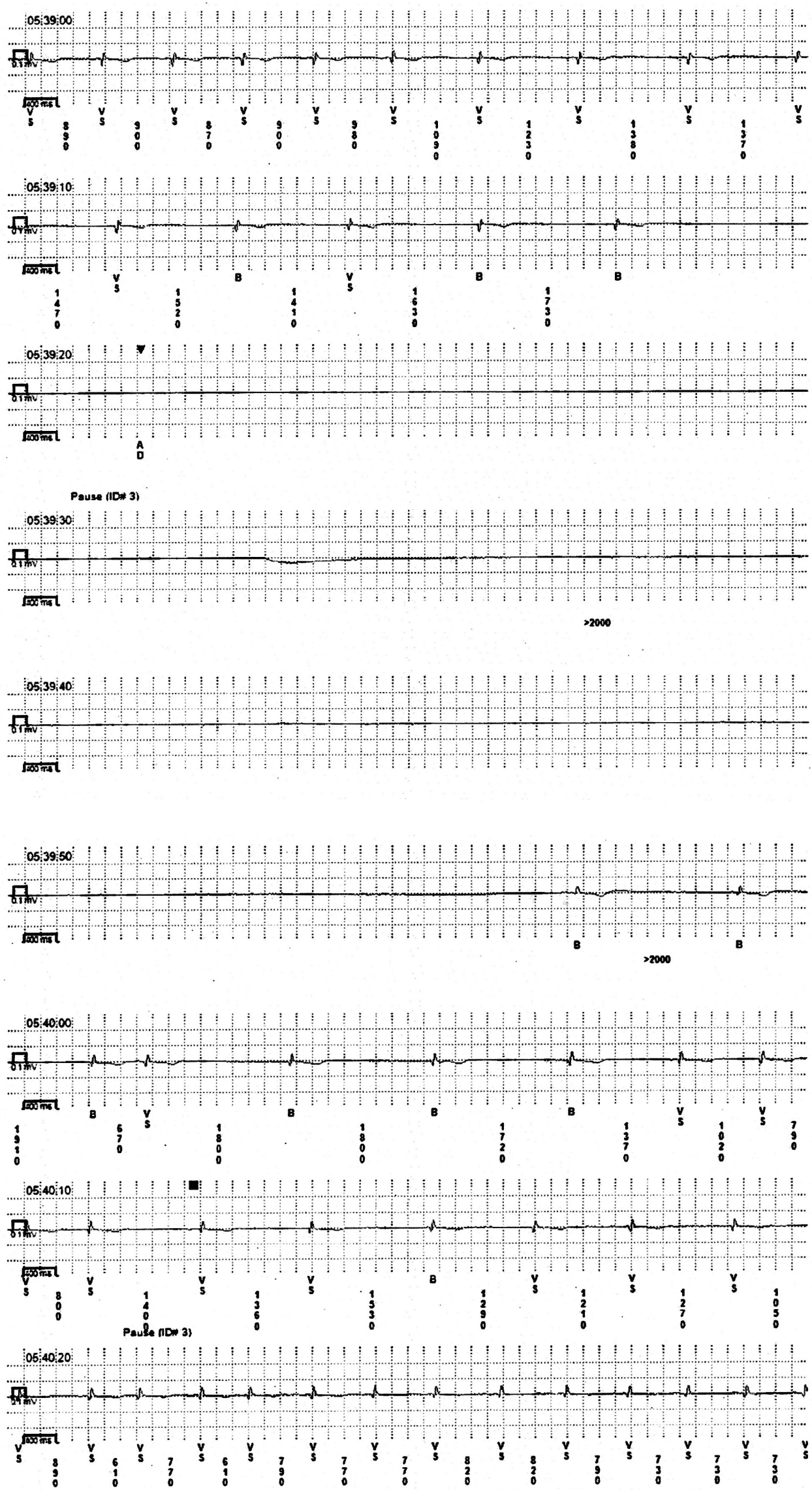

Figure 1. Internal loop recorder tracing of 39.4 second asystolic pause. 
No cause was identified for her pauses. However, she did not have tilt-table testing, electrophysiological studies or cardiac MRI scanning prior to pacemaker insertion; regardless, management would still have involved pacemaker insertion. This case reports one of the longest documented episodes of asystole with spontaneous recovery and provides a very graphic reminder of the utility of internal loop recorders in the investigation of syncope.

\section{References}

1. Maggi R, Rafanelli M, Ceccofiglio A, Solari D, Brignole M, et al. (2014) Additional diagnostic value of implantable loop recorder in patients with initial diagnosis of real or apparent transient loss of consciousness of uncertain origin. Europace 16: 1226-1230. [Crossref]

2. Varosy PD, Chen LY, Miller AL, Noseworthy PA, Slotwiner DJ, et al. (2017) Pacing as a Treatment for Reflex-Mediated (Vasovagal, Situational, or Carotid Sinus Hypersensitivity) Syncope: A Systematic Review for the 2017 ACC/AHA/HRS Guideline for the Evaluation and Management of Patients With Syncope: A Report of the American College of Cardiology/American Heart Association Task Force on Clinical Practice Guidelines and the Heart Rhythm Society. J Am Coll Cardiol 70: 664-679. [Crossref]

3. European Society of C, European Heart Rhythm A, Brignole M, Auricchio A, Baron-Esquivias G, et al. (2013) 2013 ESC guidelines on cardiac pacing and cardiac resynchronization therapy: the task force on cardiac pacing and resynchronization therapy of the European Society of Cardiology (ESC). Developed in collaboration with the European Heart Rhythm Association (EHRA). Europace 15: 1070-1118. [Crossref]

4. Mairesse GH, Marchand B (2003) Prolonged asymptomatic sinus pause indicated by implantable loop recording. Heart 89: 244. [Crossref]

5. Zaidi A, Clough P, Mawer G, Fitzpatrick A (1999) Accurate diagnosis of convulsive syncope: role of an implantable subcutaneous ECG monitor. Seizure 8: 184-186. [Crossref]

6. Deharo JC, Jego C, Lanteaume A, Djiane P (2006) An implantable loop recorder study of highly symptomatic vasovagal patients: the heart rhythm observed during a spontaneous syncope is identical to the recurrent syncope but not correlated with the head-up tilt test or adenosine triphosphate test. J Am Coll Cardiol 47: 587-593. [Crossref]

7. Menozzi C, Brignole M, Garcia-Civera R, Moya A, Botto G, et al. (2002) Mechanism of syncope in patients with heart disease and negative electrophysiologic test. Circulation 105: 2741-2745.

8. Kanjwal K, Karabin B, Kanjwal Y, Grubb BP (2010) A case of mistaken identity: asystole causing convulsions identified using implantable loop recorder. Int J Med Sci 7: 209-212.

9. Leftheriotis DI, Theodorakis GN, Kremastinos DT (2003) Prolonged asystole during head-up tilt testing with clomipramine infusion. Europace 5: 313-315. [Crossref]

10. Ali H, Sorgente A, Daleffe E, Cappato R (2014) Asystole detected by implantable loop recorders: true or false? Ann Noninvasive Electrocardiol 19: 595-597. [Crossref] 